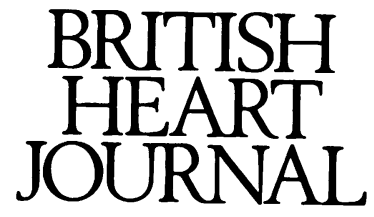

\title{
Plasma concentrations of brain natriuretic peptide: Will this new test reduce the need for cardiac investigations?
}

Atrial natriuretic peptide (ANP) was sequenced in 1984 . The discovery of ANP led inevitably to a search for other peptides with natriuretic activity. In 1988 brain natriuretic peptide (BNP) and in 1990 C-type natriuretic peptide (CNP) were identified. ${ }^{12} \mathrm{ANP}, \mathrm{BNP}$, and CNP are structurally similar but only 12 amino acids are common to all three peptides out of a total of 28 amino acids for ANP, 32 for BNP, and 22 for CNP. Though both BNP and CNP were originally identified in the porcine brain, concentrations of BNP are much higher in the heart than in the brain. The name "brain" natriuretic peptide is therefore absurd and there is a commendable tendency among the Japanese to re-name it B-type natriuretic peptide.

Normally ANP is stored in large concentrations in the atria with much less in the ventricles whereas BNP is derived to a much greater extent from the cardiac ventricles. The ventricles secrete a large amount of BNP though they store only a small quantity. Plasma concentrations of ANP are usually higher than plasma concentrations of BNP, but in cardiac failure BNP concentrations increase much more than ANP concentrations-so that in severe heart failure plasma BNP often exceeds plasma ANP. ${ }^{3}$ This differential release rate may make BNP concentrations a more sensitive indicator of left ventricular dysfunction than ANP concentrations.

The biological effects of ANP and BNP are very similar. They both cause natriuresis and vasodilatation and they both release cyclic guanosine monophosphate (GMP) and suppress aldosterone. Both are broken down by neutral endopeptidase. ${ }^{4}$ There are orally available inhibitors of neutral endopeptidase. These drugs increase BNP and ANP and it is probably because they increase both peptides that they are so potently natriuretic in heart failure. ANP but possibly not BNP is also cleared by unusual receptors called clearance receptors that bind the ANP but produce no biological effects, that is, they seem to mop up vast quantities of ANP. This seems a most curious function for these receptors but so far there is no better explanation for their role.

One of the great hopes for ANP was that it could be infused in heart failure to produce a natriuresis. ANP does cause a natriuresis in heart failure, but unfortunately not to the same extent as in healthy people. This may be due to concurrent antinatriuretic influences in heart failure such as angiotensin II or noradrenaline or it could be because ANP renal receptors are downregulated. Yoshimura et al found that infused BNP had the opposite effect to ANP in that the natriuretic response to BNP was actually higher in patients in heart failure than in controls. ${ }^{5}$ The reasons for this are unknown but this effect is another reason to think that BNP will be of more interest clinically than ANP.
There are simple and cheap radioimmunoassays for BNP and ANP. Would their use reduce the growing need for investigations, such as echocardiography, exercise ECG testing, and radionuclide ventriculography, that require expensive equipment, highly trained staff, and subjective interpretation?

Though $1.6 \%$ of a study population took diuretics for presumed heart failure only $\mathbf{0} \cdot \mathbf{8 4} \%$ had echocardiographically demonstrable systolic dysfunction of the left ventricle. ${ }^{6}$ It seems more sensible to identify the $0 \cdot 84 \%$ rather than treat all $1.6 \%$ of the population with expensive angiotensin converting enzyme (ACE) inhibitors. How many hospitals currently have the resources to perform echocardiography on $1.6 \%$ of the population? Measurement of plasma BNP (or ANP) may be a cheaper way of identifying those who require treatment. Three studies suggest that this strategy should work. In a small group of patients undergoing catheterisation Richards et al found a good inverse correlation between plasma BNP and cardiac output. ${ }^{7}$ A second hopeful sign comes from a community study of the elderly which showed that plasma ANP concentrations were raised in those who subsequently developed chronic heart failure. ${ }^{8}$ Thirdly, an N-terminal fragment of ANP had high sensitivity in detecting stage I chronic heart failure. ${ }^{9}$

Echocardiography will still be required in many patients, especially to detect valve disease in those with murmurs. Indeed, measurement of BNP concentrations may only exclude normal hearts: but this alone could halve the echocardiographic burden. Those with a high peptide concentration and no murmur may, however, be another group in whom echocardiography could be omitted.

Perhaps assay of plasma BNP (or ANP) will more cheaply give the same information on left ventricular ejection fraction as radionuclide ventriculography (RNV). Poor echogenicity is one of the indications for performing RNV. RNV is more objective than echocardiography but requires a dose of radioactivity. Many district general hospitals in the United Kingdom do not have RNV equipment.

The SAVE (Survival and Ventricular Enlargement) showed that treatment with an ACE inhibitor reduced mortality by $19 \%$ in patients in whom the left ventricular ejection fraction (LVEF) was $\leqslant 40 \%$ after myocardial infarction. We recently found that a raised BNP concentration identified symptom free patients with a left ventricular ejection fraction of $<40 \%$ after myocardial infarction..$^{10}$ As expected plasma ANP was not as predictive as BNP. Measurement of BNP will be unnecessary when all patients who have had myocardial infarction can be examined by echocardiography, as they usually are in 
large teaching hospitals. But in district general hospitals a BNP test may be helpful. In as yet unpublished work, we found that an LVEF of $\leqslant 40 \%$ was not reliably detected by several clinical scoring systems: they missed many of those with an LVEF $\leqslant 40 \%$. The criteria on which patients are selected for ACE inhibitor therapy after myocardial infarction may change in the light of the soon to be reported results of large studies such as ISIS-4 (fourth International Study of Infarct Survival) and GISSI-3 (Gruppo Italiano per lo Studio della Streptochinasi nell'Infarto Miocardico).

One other intriguing possibility is that plasma ANP or BNP concentrations reflect ischaemia. The idea is that ischaemia leads to systolic or even diastolic dysfunction, both of which will increase ANP or BNP concentrations. One clinical study has indeed shown that exercise increases plasma ANP more in patients with angina than in those without. ${ }^{11}$ Though this does not obviate the need for exercise testing, any measure that helps in interpreting the many equivocal exercise tests is welcome.

There are several other possible uses (box). Because

\begin{tabular}{|l|}
\hline \multicolumn{1}{|c|}{$\begin{array}{c}\text { Possible uses of plasma BNP } \\
\text { concentrations }\end{array}$} \\
\hline - Detecting early heart failure \\
- Replacing radionuclide ventriculography \\
- Identifying left ventricular dysfunction after \\
myocardial infarction \\
- Assisting in diagnosis of myocardial ischaemia \\
- Detecting left ventricular hypertrophy in \\
- Pypertension \\
\hline
\end{tabular}

the greatest risk in hypertensive patients is the development of left ventricular hypertrophy, a case can be made for performing echocardiography in all hypertensive subjects to stratify risk and target intensive treatment. Plasma ANP is indeed higher in those with left ventricular hypertrophy, but plasma BNP is likely to be a better identifier because it is mainly a ventricular hormone. ${ }^{12}$ BNP concentrations may identify hypertrophic obstruc- tive cardiomyopathy earlier than echocardiography, which is fraught with problems when used to screen for hypertrophic obstructive cardiomyopathy (HOCM). ${ }^{13} 14$

There are, however, some pitfalls. Concentrations of ANP and BNP are also raised in renal failure, cor pulmonale, and in severe isolated diastolic dysfunction. The first two of these should be readily detected during routine clinical assessment. It remains to be seen how much of a problem diastolic dysfunction will be in interpreting ANP and BNP concentrations.

ALLAN D STRUTHERS

Department of Clinical Pharmacology,

Ninewells Hospital, Dundee DD1 $9 S Y$

ADS thanks the British Heart Foundation for the award of a grant to investigate some of the above ideas.

1 Sudoh $\mathrm{T}$, Kangawa $\mathrm{K}$, Minamino $\mathrm{N}$, Matsuo $\mathrm{H}$. A new natriuretic peptide in porcine brain. Nature 1988;332:78-80.

2 Sudoh T, Minamino N, Kangawa K, Matsuo H. C-type natriuretic peptide (CNP): a new member of the natriuretic peptide family identified in porcine brain. Biochem Biophys Res Commun 1990;155:726-32.

3 Mukoyama $\mathbf{M}$, Nakao $\mathrm{K}$, Hosda $\mathrm{K}$, et al. Brain natriuretic peptide as a novel cardiac hormone in humans. F Clin Invest 1991;87:1402-12.

4 Lang CC, Motwani JG, Coutie W, Struthers AD. BNP clearance in chronic heart failure: evidence for a neutral endopeptidase mechanism but against an ANP clearance receptor mechanism. Clin Sci 1992;82. 619-23.

5 Yoshimura M, Yasue H, Morita E, et al. Haemodynamic, renal and hormonal responses to BNP in patients with congestive heart failure. Circulation 1991;84:1581-8.

6 Wheeldon N, MacDonald T, Flucker CJ, McKendrick A, McDevitt D, Struthers AD. Echocardiography in chronic heart failure in the community. Qf Med 1993;86:17-24.

7 Richards AM, Crozier IG, Yandle TG, Espiner EA, Ikram H, Nicholls MG. Brain natriuretic factor: regional plasma concentrations and correlations with haemodynamic state in cardiac disease. Br Heart $\mathcal{F} 1993$; 69:414-7.

8 Davis KM, Fish LC, Elaki D, Clark BA, Minaker KL. ANP levels in the prediction of CHF risk in the frail elderly. $¥ A M A 1992 ; 267: 2625-9$.

9 Lerman A, Gibbons RJ, Rodeheffer RJ, Bailey KR, McKinley LJ, Heublein DM, Burnett JC. Circulating N-terminal ANP as a marker for symptomless left ventricular dysfunction. Lancet 1993;341:1105-8.

10 Motwani JG, McAlpine H, Kennedy N, Struthers AD. Plasma BNP as an indicator for ACE inhibition after myocardial infarction. Lancet 1993, 341:1109-13.

11 Hu DCK, Wong EFC, Wong NLM. The differential response in ANF release during exercise in patients with and without ischaemic heart disease. Am F Med Sci 1988;296:111-3.

12 Montorsi P, Tonolo G, Polonia J, Hepburn D, Richards AM. Correlates of plasma ANF in health and hypertension. Hypertension 1987;10: of plas

13 Clark AL, Coats AJS. Screening for hypertrophic cardiomyopathy. Br Med f 1993;306:409-10.

14 Yoshibayashi M, Kamiya T, Saito Y, Matsuo H. Increased plasma levels of brain natriuretic peptide in hypertrophic cardiomyography. $N$ Engl $\mathcal{F}$ Med 1993;329:433-4. 